

PEB Exchange, Programme on Educational Building 2008/06 


\section{Evaluating School Facilities in Brazil}

\section{By Sheila Walbe Ornstein, FAUUSP, and Nanci Saraiva Moreira, FDE, Brazil}

Brazil's São Paulo Metropolitan Region is conducting a performance evaluation pilot study at three schools serving disadvantaged populations. The objective is first to test methods which can facilitate Post Occupancy Evaluations (POEs) and then to carry out the evaluations. The preliminary results are provided below.

The São Paulo State public school system comprises over 5500 buildings and serves some 5.2 million students between the ages of 7 and 17. A large number of these students, about 2722 000, live and study in the São Paulo Metropolitan Region, comprised of the city of São Paulo and numerous contiguous municipalities.

Methods are needed to facilitate performance evaluations of school buildings, and it is important that the evaluations be oriented, at least in part, towards the schools' educational projects and user satisfaction. With this in mind, a group of international experts, under the auspices of the OECD Programme on Educational Building (PEB), is preparing a facilities performance evaluation manual, covering all stages from pre-design to post-occupancy. In this context, the Faculty of Architecture and Urbanism of the University of São Paulo (FAUUSP) has joined hands with the São Paulo State Department of Education (SEE) and its Foundation for the Development of Education (FDE), an organisation established to speed up construction and improve the quality of the school buildings. Graduate students ${ }^{1}$ in the University of São Paulo's course on Post Occupancy Evaluation of Built Environments participated in the first phase of the pilot study which took place during the first semester of 2007, from February to July.

The schools chosen for the pilot studies are located in neighbouring districts of two different municipalities of the São Paulo Metropolitan Region: the Pantanal District of the Municipality of São Paulo and the neighbourhood known as Jardim Leblon in the Municipality of Guarulhos. Although these two municipalities are among the most economically developed in Brazil, the students who frequent the pilot study schools are poor, especially those in the Pantanal District, which also suffers from a high crime rate. Illegal housing has recently developed in this district, in the form of squats, largely in protected environmental areas; once these areas have been occupied and houses built, public authorities have difficulty providing the necessary urban services.

1. The authors wish to thank the graduate students who participated: A.E. Resende, A. D'Angelo Leitner, B.C. de Souza Godoi, C.T. Pereira Pires, C. Mizuki Umetsu, F. Preto Lazzaretti, H. Quintana Minchin, M. Mantovani Teixeira, M. de Lourdes Jovaneli, M. Sarquis Ude, N. Raunec Civile, R.S. Bento Guimarães and W. Furlan. 


\section{THE SCHOOLS}

\section{Helio Helene and Prof. Paulo Kobayashi state schools}

In the Pantanal District the pilot study was carried out at two state schools, Helio Helene and Prof. Paulo Kobayashi, which are both housed in the same building. The Helio Helene School serves 1007 primary school students (aged 7 to 10), and the Prof. Paulo Kobayashi School, 646 secondary students (aged 11 to 17). Both schools offer classes to one set of students in the morning and to another in the afternoon.

The building offers $6840 \mathrm{~m}^{2}$ of space and occupies a site measuring $4260 \mathrm{~m}^{2}$ (a daycare centre was also built on the site). The building was constructed in 2005 and put in use in 2006. Its structural system is made of precast concrete, the current standard of the Department of Education's Foundation for the Development of Education (FDE). The building is divided into two wings, one used by the primary school and the other by the secondary school, with separate administrative structures.

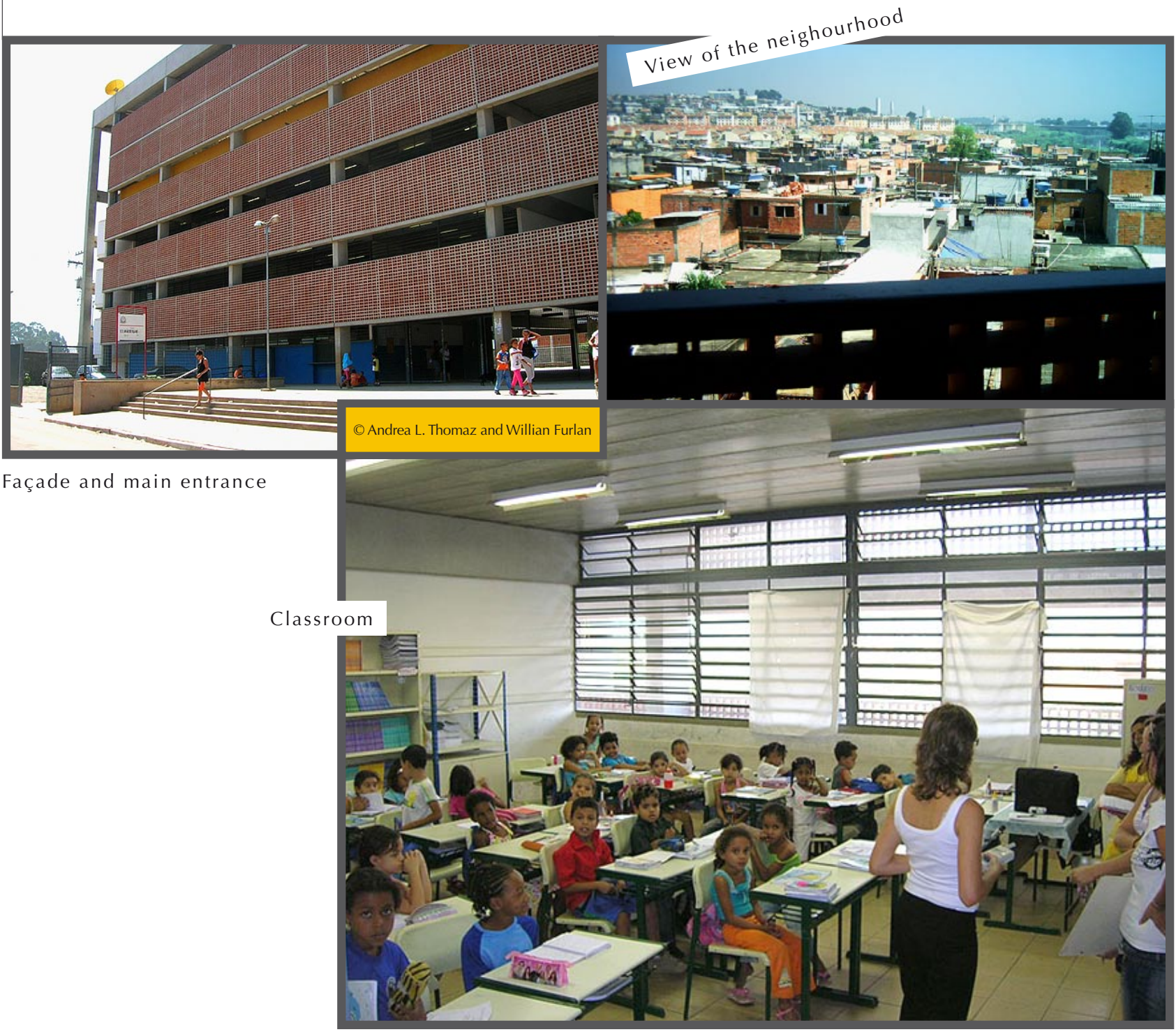


The Department of Education decided to house two schools in a single building due to the lack of land available for two separate schools in this region. At the time, the only piece of land available and large enough for the construction of adequate school facilities consisted of a soccer field. As the field was also the only area in the neighbourhood that was free for leisure activities, the state negotiated with the local community and agreed to cede use of the sports area outside of class hours.

As a result of these space limitations, the city government exempted the building from the standard regulations on construction setbacks.

\section{Profa. Marinha Ferreira do Nascimento State School}

The building evaluated in Jardim Leblon, the Profa. Marinha Ferreira do Nascimento State School, has a constructed area of $1760 \mathrm{~m}^{2}$ and was built on a $2195 \mathrm{~m}^{2}$ tract of land. This public school is attended by 784 primary school students, half in the morning and half in the afternoon. The site was previously occupied by a pre-fabricated school building installed in 1978 to urgently address the growing demand for schools in the wake of the rapid demographic growth then occurring in the Greater São Paulo Region. The present building was constructed in 2003 and occupied in 2004, and was based on conventional construction processes (concrete cast in situ).

Both buildings were built in conformity with the needs defined by the FDE, which are based on the guidelines in the educational policies in effect. The design guidelines were attentive to construction costs, efficiency and low maintenance.

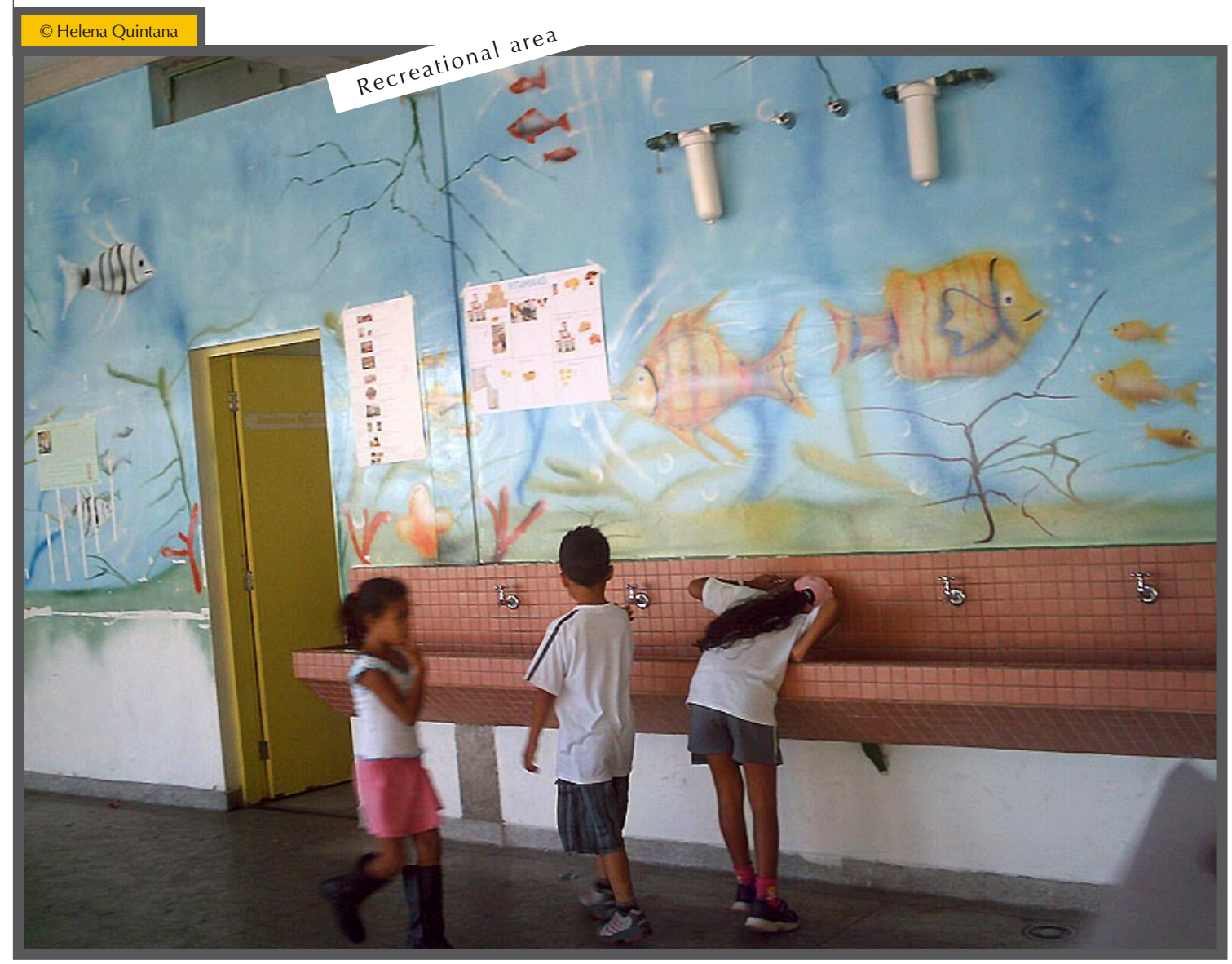




\section{WHY THESE BUILDINGS}

The criteria for choosing the two buildings for the pilot study were the following:

1. The broad range of age brackets that use the school, in order to better understand how students, in the various stages of their school life, perceive the physical space and environmental comfort the school building provides.

2. Schools having potential educational projects associated with developing architecture.

3. Schools occupied for more than one year and less than five, and having representative "state-ofthe-art" architecture.

4. Schools whose design differs from the standards used by the public school system; in other words, schools whose architecture is specific to their location, respecting the design guidelines issued by the FDE. This is especially true for the Helio Helene and Prof. Paulo Kobayashi schools, whose architectural qualities resulted from a successful partnership between two architectural firms, from the FDE's follow-up on the evolution of the design, and from the systematic monitoring of the construction work by the architects themselves; the architects, in conjunction with the construction company and technicians on the FDE's design and public works teams, decided on various details of the processes during the actual construction of the buildings.

\section{POST OCCUPANCY EVALUATION}

The methods to evaluate the buildings used by experts and users, including students, teachers, other staff and parents include:

\section{Experts' methods}

- Studying of the complete construction designs, including aspects related to the modular co-ordination adopted.

- Analyses of interviews held with the FDE personnel who were responsible for designs, works and furniture.

- Analyses of interviews held with the architects and constructors.

- Drafting of checklists to guide technical inspections and walkthroughs.

- Walkthroughs and inspections to verify the performance of the construction systems.

- Ergonomic measurements to determine furniture use in relation to the types of users (from children to adults).

- Measurements of environmental comfort (ventilation, temperature, natural and artificial lighting, energy efficiency, acoustics, etc.).

- Walkthroughs in the immediate neighbourhoods to analyse the urban context where the schools are located.

\section{Users' methods}

- Interviews with school principals.

- Conducting of teacher and student questionnaires with value scales and measurements of satisfaction levels.

- Creation of teacher and student focus groups, sometimes followed by walkthroughs.

- Cognitive maps (drawings by the smaller children).

- Maps of activities and behaviour. 


\section{Results}

The preliminary results of the pilot study show needs in the following areas:

- Increase in the number of pre-fabricated components for the architectural composition.

- Specific studies on lighting, temperatures and acoustics, carried out by experts in conjunction with the architects responsible for the designs. Where solar control devices are used on façades this is especially important, not only for the quality of the lighting in study spaces, but also as relates to temperatures and ventilation. The study's final results will likely address acoustic comfort, specifically the conflict between the noise levels of sports/recreational and eating areas, on the one hand, and learning environments, on the other.

- Closer relationship between the quality of the architecture and the quality and type of educational project.

- Development of participatory designs (architects together with the community).

- Verification of costs for both construction and maintenance, based on the design guidelines.

- Closer relationship between the school facilities and the urban context.

\section{MOVING FORWARD: A META-EVALUATION}

A second phase of this pilot study began during the second semester of 2007 and is continuing into the first months of 2008. It is being carried out at the Fernando Gasparian State School at Campo Limpo, District of the Municipality of São Paulo. The school serves more than 1800 primary and secondary students over its morning, afternoon and night periods. The design process and the building's construction were largely based on the same approach as the Helio Helene and Prof. Paulo Kobayashi state schools.

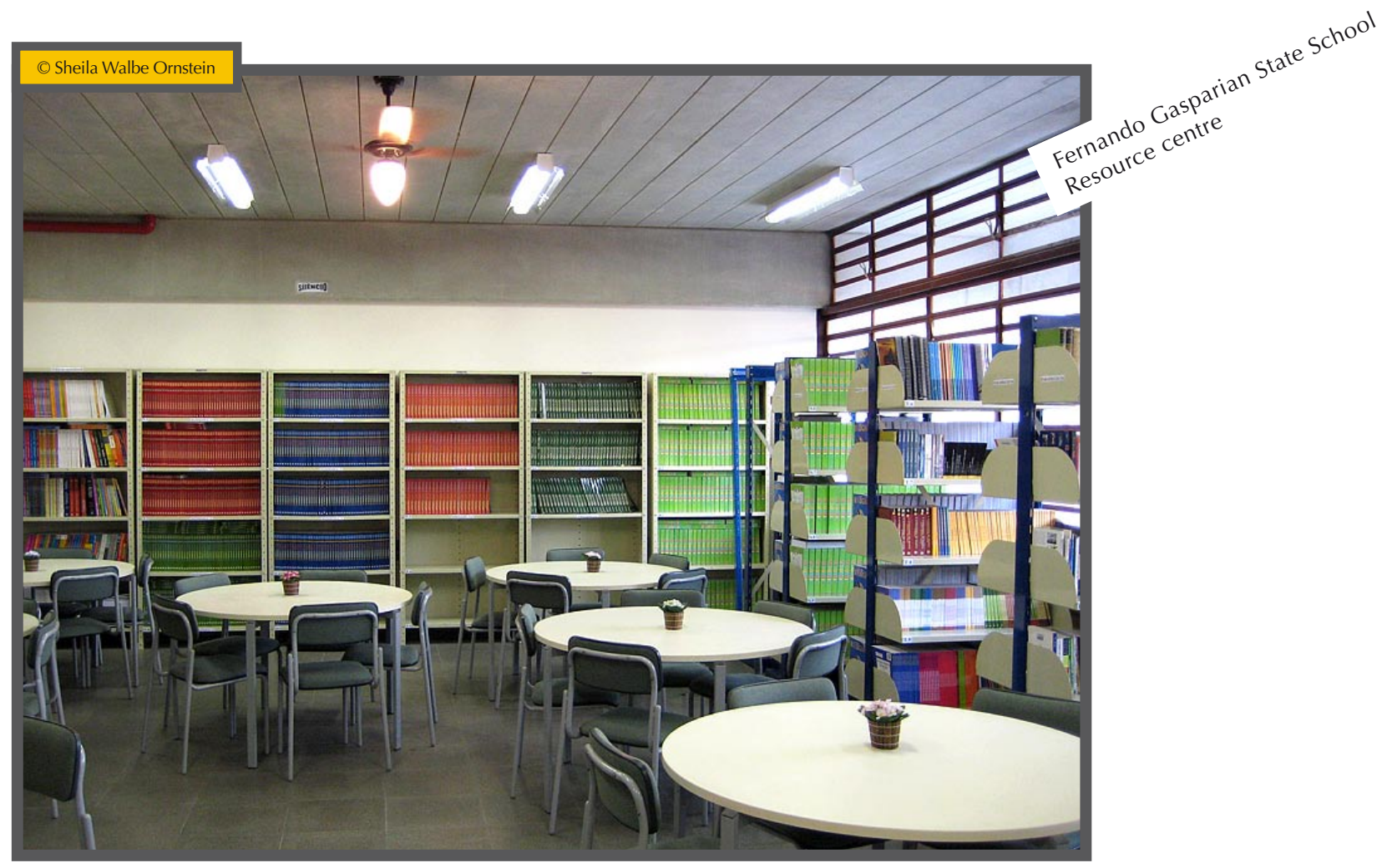


A meta-evaluation of the methods tested in the first phase of Brazil's evaluation process is planned. It will provide additional data for both the FDE/SEE/FAUUSP evaluation procedures and PEB's future Facilities Performance Evaluation manual.

For more information, contact:

Dr. Sheila Walbe Ornstein

Architect and Urbanist

Full Professor, Faculty of Architecture and Urbanism

University of São Paulo (FAUUSP)

Researcher, National Scientific and Technological Development Board (CNPq)

Brazil

E-mail: sheilawo@usp.br

Dr. Nanci Saraiva Moreira

Architect and Urbanist

Foundation for the Development of Education (FDE)

São Paulo State Department of Education (SEE)

Brazil

E-mail: nanci.moreira@fde.sp.gov.br

or visit:

Faculty of Architecture and Urbanism of the University of São Paulo: www.usp.br/faul Foundation for the Development of Education: www.fde.sp.gov.br/

São Paulo State Department of Education: www.educacao.sp.gov.br/ 


\section{ORGANISATION FOR ECONOMIC CO-OPERATION AND DEVELOPMENT}

The OECD is a unique forum where the governments of 30 democracies work together to address the economic, social and environmental challenges of globalisation. The OECD is also at the forefront of efforts to understand and to help governments respond to new developments and concerns, such as corporate governance, the information economy and the challenges of an ageing population. The Organisation provides a setting where governments can compare policy experiences, seek answers to common problems, identify good practice and work to co-ordinate domestic and international policies.

The OECD member countries are: Australia, Austria, Belgium, Canada, the Czech Republic, Denmark, Finland, France, Germany, Greece, Hungary, Iceland, Ireland, Italy, Japan, Korea, Luxembourg, Mexico, the Netherlands, New Zealand, Norway, Poland, Portugal, the Slovak Republic, Spain, Sweden, Switzerland, Turkey, the United Kingdom and the United States. The Commission of the European Communities takes part in the work of the OECD.

OECD Publishing disseminates widely the results of the Organisation's statistics gathering and research on economic, social and environmental issues, as well as the conventions, guidelines and standards agreed by its members.

This work is published on the responsibility of the Secretary-General of the OECD. The opinions expressed and arguments employed herein do not necessarily reflect the official views of the Organisation or of the governments of its member countries.

No reproduction, copy, transmission or translation of this publication may be made without written permission. Applications should be sent to OECD Publishing rights@oecd.org or by fax 331452499 30. Permission to photocopy a portion of this work should be addressed to the Centre français d'exploitation du droit de copie (CFC), 20, rue des Grands-Augustins, 75006 Paris, France, fax 331463467 19, contact@cfcopies.com or (for US only) to Copyright Clearance Center (CCC), 222 Rosewood Drive, Danvers, MA 01923, USA, fax 1978646 8600, info@copyright.com. 